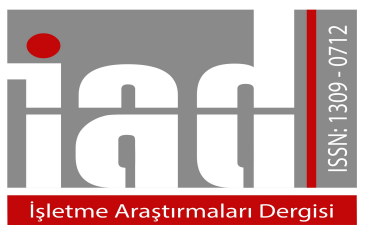

Journal Of

Business Research

Turk

\title{
Banking Websites in Turkey: an Accessibility, Usability and Security Evaluation
}

\author{
Yakup AKGÜL \\ Alanya Alaaddin Keykubat University \\ Faculty of Business Administration \\ Alanya, Antalya, Turkey \\ orcid.org/0000-0001-5344-4359 \\ yakupakgul@gmail.com
}

\begin{abstract}
With the proliferation of the Internet, banks are adopting technologies to create their own Websites. Websites have evolved into an excellent means of information dissemination and visibility. Hence banks and organizations around the world have websites as primary medium for information communication. The information in bank web sites, which are broadly assumed in numerous nations, must be accessible for all people, easy to use, exact and secure. Since the web is a significant assets of information for millions of people at all levels, attaining accessible e-banking services that enable customers to gain from them and execute varied customers' prerequisites, regardless of time and location constraints, has become a global aim. The main aim of this study is to investigate the accessibility, usability and vulnerability of Turkish banking websites. A total of thirty two banking websites in Turkey were analyzed according to the criteria of the WCAG 2.0 guidelines, and all of them was selected for further analysis based on usability and vulnerability criteria. The results showed that the evaluated websites had significant number of accessibility, usability and vulnerability problems.
\end{abstract}

Keywords: Usability · Accessibility · banking websites · vulnerability $\cdot$ WCAG Web Content Accessibility Guidelines WCAG 2.0

\section{Introduction}

The higher penetration of information and communication technology (ICT) has become an inescapable part of everyday life in precisely the Internet (La Porte et al., 2001). The Internet has transform into a significant source of information and communication all over the World, offers an occasion for banks to propose services to their customers via websites and mobile applications. Bank websites supply a platform for efficient customer relationship and access to their own financial requirements. The Turkish Statistical Institute reports that over fourty-three percent of Turkish adults now own tablets (TSI, 2017), and ninety-seven percent of Turkish adults use mobile phone (incl. smartphones) (TSI, 2017). 
There was an estimate of 3.5 billion internet users worldwide in 2016. Out of these, 46,196,720 million Internet users in Turkey (Statista, 2017; Internetlivestats, 2017). Websites are playing a major role for enhancing absolutely prominent as a means of customer relations and offering information to everyone regardless of their disability. In this way, websites and mobile applications should be usable, accessible, well coded, secured and mobile-device ready. In view of the fact that the number of disabled individuals in Turkey, based on the Turkey Disability Survey (TSI, 2002), 8,431,937 Turkish persons have disabilities; $12.29 \%$ the disability people stand for Turkey's whole population. Two variety of disability was listed by survey: orthopedic, and then vision, hearing, communication and intellectual disabilities, which include autism spectrum disabilities. Among the five types of disabilities on which data was collected, percentage of orthopedic, vision, hearing, communication and intellectual disabilities were $(2.58 \%)$, chronic illness $(9.70 \%)$; and the unspecified disabilities have represented the remainder of the population. Percentage of orthopedic, vision, hearing, communication and intellectual disabilities was $2.58 \%$; chronic illnesses was $9.70 \%$; and the remainder of the population have represented by the unspecified disabilities (Firat, 2010). The percentage of orthopedic, vision, hearing, communication, and intellectual disability is higher in rural than urban regions and the extent of disability increases by age while the extent of chronic illnesses are higher in urban than rural regions (Firat, 2010). World Health Organization estimated the proportion of the disability close to the $15 \%$ rate in Turkey (WHO, 2011), demographers (Quinn, 2009) and the United Nations (United Nations Enable, 2013). Auditory, cognitive, neurological, physical, speech disabilities are affected by website accessibility. And also, older people confront several obstacles based on vision decline, hearing loss, decremented motor skills and cognition issues are affecting the usage of the web due to diminishing capacities related to aging. Accessible websites ensure banks the occasion to connect to guarantee equal access for everyone regardless of their disability, which consitute a significant market fragment.

It is vital that the accessibility of web overwhelming all disabilities that influence Internet Access, accessible to a wide array of possible users regardless of their technical aptitude or possible disabilities. More specifically, people with disabilities can use it and perceive, understand, navigate, contribute and interact with the Web. Therefore, the accessibility of web can be regarded as an innovation for the relationship between the organization and all their stakeholders, which becoming a source of competitive advantage for businesses (Frankelius, 2009; Thorp and Henry, 2008). And also, web accessibility has human rights, ethical and social responsibility aspects. Absolutely, assuring web accessibility for banking websites is not a goods, it is crucial that ensuring all users have equal access to information and functionality and to supply the protection of equal human rights. In fact, in 2006, the UN Assembly passed a Treaty on Rights of Disabled that would guarantee persons with disabilities equal access to ICT. To respond to this Treaty, Turkey in June 2008 has signed and ratified this UN Treaty (UN, 2017). Regardless of its significance, there is a gap in the research about the reasons underlying the intensity of web accessibility, usability and vulnerability among banks.

In this study, Turkish banking websites have been investigated based on website accessibility, usability and vulnerability. Websites of Turkish banks have been chosen, because of the internet banking is growing very fast in Turkey, and it is existed as a significant means of distribution of financial services, it is essential that all individuals 
must have equal accessible opportunities to all financial services. According to the Banks Association of Turkey; the number of active digital banking customers exceeds 32 million people in Turkey (BAT, 2017). Internet banking is receiving the banking services without any limit in time and location with an internet and a computer or a mobile device as an alternative service channel, since Internet access is available. The raise of accessible websites are guaranteed equal access for everyone regardless of their disability.

\section{Review of the Literature}

Over the past few years, many studies have been utilized to examine the assessent of banking Web sites from many different aspects using different models. Zhang and Dran (2001) and Diniz et al. (2005) introduced a research model to investigate and comprise digital business environment based on the user's approach, though some researchers assessed e-banking websites and the e-banking service quality according to a certain research model (Vijayan and Shanmugam, 2003; Wenham and Zaphiris, 2003; Achour and Bensedrine, 2005). Other researchers adopted the previous models to evaluate Internet banking websites through their studies. For example, Guru et al. (2003) evaluated the internet banking sites of Islamic countries based on a Diniz's model. Paynter and Chung (2002) investigated New Zealand by using Herey's Model for website examination. Awamleh and Fernandes (2005) evaluated the websites of foreign and local banks in the United Arab Emirates based on the Diniz's model. Lichtenstein and Williamson (2006) accessibility, perceived security, self-efficacy, convenience and usability attributes affecting the consumers' online banking decision without performance expectancy, social influence, facilitating conditions and attitude.

In context of accessibility studies; Celic et al. (2004) evaluated the home pages of the eight official domestic banks in Australia. The results of study showed that none of the banks fully complies with the Web Content Accessibility Guideline (WCAG). Martins et al. (2010) examined Portuguese banks websites conform to W3C Web Content Accessibility Guidelines 2.0. The results of examination revealed a severe lack of accessibility issues in the investigated websites. Nouman (2012) examined the accessibility issues of different financial websites of Pakistan. Kaur and Dani (2014) has conducted the study to find some common accessibility errors among banking websites according to WCAG 2.0 in India.

Some similar studies on evaluating of the banking web sites and web contents were also conducted like usability (Chin-Shan and Cheng, 2004; Wenham and Zaphiris, 2003; Orji, 2010), accessibility (Ali, 2007; Thechnosite group, 2004; Orji, 2010; Lorca et al., 2015; Martínez et al., 2014) functionality (Eduardo et al., 2005), navigability ( Bonsón-Ponte et al., 2008; Kaur and Dani, 2013), internet banking service quality (Wenham and Zaphiris, 2003; Achour and Bensedrine, 2005; Vijayan and Shanmugam, 2003), etc. To the best of authors' knowledge, this is the first study to assess the banking websites for the accessibility with the disabled users, usability and vulnerability in context of Turkey.

\section{Methodology \\ 3.1.Materials}

For the usability analysis of the banking websites, the WebSiteOptimization tool was utilized. The calculation of page size, composition and download times for a given web site conducted by this tool and was used in the analysis (Jati and Dominic, 2009; 
Manhas, 2014; Ismailova, 2015; Akgül, 2016a; Akgül, 2016b). Fast Link Checker: for navigation usability tool which was used to assess the site's broken link, response time, download time, size and total objects on a webpage measured and evaluated by "webpage speed analyser". Response time is measured by websitepulse. Load time is measured to calculate the time required to load a page and its graphics by pingdom tool. To examine the mobile loading of banking Web sites, the study used Google's pagespeed test (Pagespeed, 2017), which analyzes a given URL and rates the degree to which its mobile loading. Webaim is used for current use of HTML5 and ARIA. For HTML and CSS examining the code on each home page, and involved validation of (X)HTML (W3, 2017), validation of the CSS (W3, 2017).

W3C provides a list of many evaluative tools (W3C, 2017) and also recommends WCAG v. 2 over v. 1 (W3C, 2017). Among the list, AChecker, which proved to provide the most accurate results during the author's previous studies, was also utilized for this study (ATRC, 2017). Also, the SSLv3 POODLE vulnerability scanner tool were used for security tests.

\subsection{Procedure}

This study evaluates the accessibility, usability and vulnerability of Turkish bank web sites and presents study is to find out if web accessibility, usability and vulnerability differs among banks. In this study, the 32 the official website of the banks' homepages have been analysed from three points of view: web accessibility, usability and vulnerability evaluation, each site's homepage was selected from The Banks Association of Turkey website. The Banks Association of Turkey is a professional organization, which was founded in 1958, a legal entity with the status of a public institution, established pursuant to Article 19 of the Banks Act. Banking Industry in Turkey comprises of deposit banks and development and investment banks. The deposit banking structure is further classified into state-owned banks, privately-owned Banks and foreign banks having branches in Turkey. Banks Under the Deposit Insurance Fund and Foreign Banks has been excluded from analysis (BAT, 2017). Currently, Turkey has 32 deposit banks, 3 public sector banks, 9 private banks and 20 foreign banks (BAT, 2017). The main aim of this study is to investigate the accessibility, usability and vulnerability of the Turkish deposit banks' websites. The data for 32 websites listed under public, private sector banks and foreign banks were collected.

\section{Results}

\subsection{Accessibility Analysis}

Many evaluative tools are listed by W3C (W3C, 2017) and also it is recommended by WCAG v. 2 over v. 1 (W3C, 2017). Among the list, AChecker, which proved to provide the most accurate results during the author's previous studies (Akgül and Vatansever, 2016a; Akgül and Vatansever, 2016b; Akgül, 2016a; Akgül, 2016b), was also utilized for this study. AChecker was developed by ATRC at the University of Toronto. Web sites were determined the conformance levels of banking websites in Turkey to Web Content Accessibility Guidelines (WCAG) 2.0 and the errors categorized by level 3 priority checkpoints and examined which macro factors influenced and impacted the accessibility these websites. According to (W3, 2017), these priorities are as follows:

[Priority 1]: A Web content developer must satisfy this checkpoint. Otherwise, one or more groups will find it impossible to access information in the document. Satisfying this checkpoint is a basic requirement for some groups to be able to use web documents. 
[Priority 2] A Web content developer should satisfy this checkpoint. Otherwise, one or more groups will find it difficult to access information in the document. Satisfying this checkpoint will remove significant barriers to accessing web documents.

[Priority 3] A Web content developer may address this checkpoint. Otherwise, one or more groups will find it somewhat difficult to access information in the document. Satisfying this checkpoint will improve access to web documents.

Web site markup code is very significant the validation of its accessibility. A miscoded web site will be examined according to obstacles by the most of assistive technologies. It is the first step the homepages was validated by using the $\mathrm{W} 3 \mathrm{C}$ online validator. The assessment pointed out that 3 (out of 32) banking web sites have conformance level A (conform to W3C's "Web Content Accessibility Guidelines 2.0," and sixteen of the web sites have conformance level AA. Thus, banking web sites in the Turkish Republic have accessibility error rates for priority 1, 2 and 3 checkpoints of 79, 0,07 and $14 \%$, respectively (Table 1 ). The 32 Turkish banking web sites' home pages that were analyzed comprised a total of 3982 WCAG 2.0 failed success criteria for level (A, AA, AAA). Out of these, 3152 were Level A errors, 283 were Level AA errors and 547 were Level AAA errors (Table 1).

The analysis was fulfilled on 32 banking Web sites from the operating four types of comprises of banks. The analysis of 32 web pages available resulted in average accessibility issues per priority 1 (98,75 issues), priority 2 (9,625 issues) and priority 3 (17 issues). The results of the analysed websites, the state-owned banks have on average a number of accessibility errors of Level A was 46, 136 in privately-owned banks, 116 in the foreign banks, 9 in the foreign banks having branches in Turkey. With regard to Level A failed success criteria, the bank websites of the foreign banks had the smallest average number errors, though average number of priority level AAA errors. For Level A failed success criteria, privately-owned banks websites have the highest number of failed success criteria (Fig. 1; Fig. 2).

\section{Fig. 1 Different Bank Web sites with corresponding average number of parsing} errors

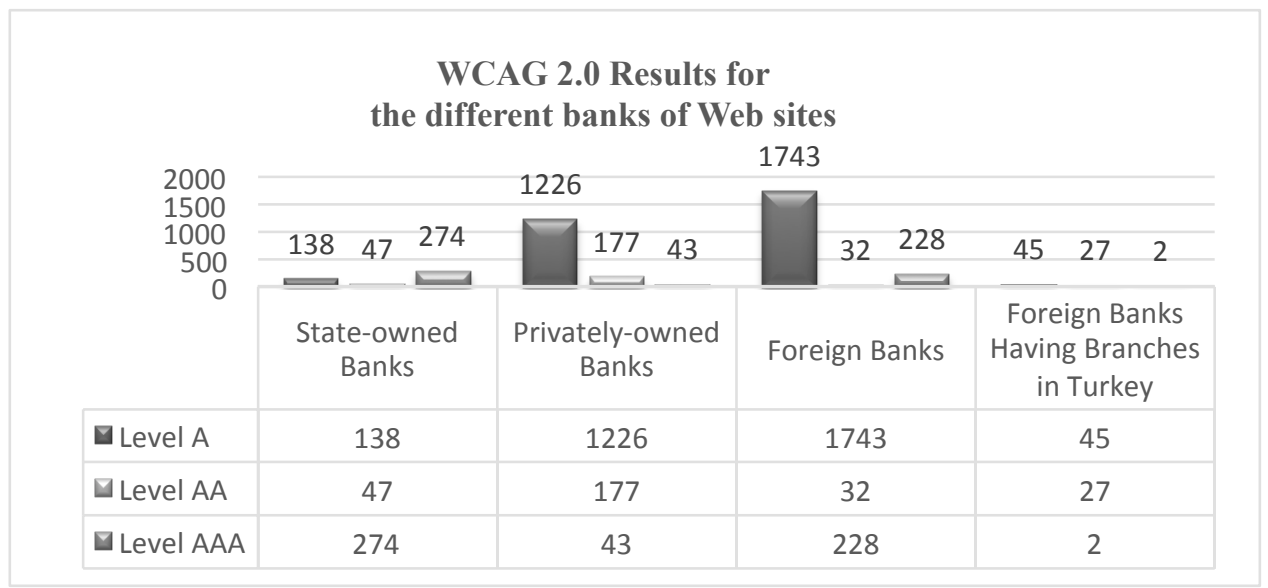


Fig.2 WCAG 2.0 Results for the different Bank Web sites

\begin{tabular}{|r|r|r|r|}
\hline \multicolumn{5}{|c|}{ Average failed success criteria for bank websites using automatic } \\
tools
\end{tabular}

Figure 2 depicts the average number of parsing errors according to different banking websites. Most of the errors have appeared in the Privately owned bank and the Web sites of Foreign banks, with 161 and 133 average errors, respectively. On the other hand, Foreign banks having branches in Turkey Web sites have the least parsing errors (Avg. 14,4). After the assessment of the banking websites using W3C markup validator, each website was manually checked based on the WCAG 2.0 success criteria checkpoints. Figure 2 depicts the average failed success criteria in each category of the banking types. The most failed success criterion appeared in Level A were SC 1.1.1 Further investigating the failed success criteria, it was found that the most failed success criteria include: SC 1.1.1 Provide a text equivalent for every non-text element (e.g., via "alt", "longdesc", or in element content), many banking web sites violated this checkpoint, which is one of the most significant and essential qualifications of accessible websites. State-owned Banks and Privately-owned Banks provided a text equivalent for more non-text elements and thus violated checkpoint 1.1.1 less. SC 1.3.1 (Info and Relationships), and SC 3.2.2 (On Input). SC 1.3.2 Meaningful Sequence, 2.1.1 (No Keyboard access). This success criterion ensures that everything in a Web page is available from the keyboard. Failing to provide easy access to a Web site will affect users with mobile impairments who rely only on the keyboard to operate a Web site, SC 2.4.1 (no link is provided to skip navigation), SC 2.4.4 Link Purpose (In Context), SC 3.1.1 Language of Page: The default human language of each Web page can be programmatically determined. The results of the study demonstrated that nearly half of the Web sites (21 out of 32 tested Web sites) failed to identify the primary natural language of documents. SC 3.2.2 On Input, the analysis for compliance with WCAG 2.0 showed that checkpoint 3.2.2 was violated in website of the foreign banks eighteen times. SC 3.3.2 Labels or Instructions: Labels or instructions are provided when content requires user input. Many Web sites in the thirty two banking Web sites also fail to meet the requirements of checkpoints 3.3.2 (each input element must have only one associated label). SC 4.1.1 Parsing: Proper nesting of HTML elements and use of unique CSS IDs. and SC (4.1.2 Name, Role, Value). Furthermore, All types of banking Web sites have absolutely the different failed Level A success criteria, with Foreign banks having branches in Turkey Web sites having the least failed success criteria. Interestingly, Level AA conformance was the least in the number of errors occurring among all variety of banking Web sites. For these reasons, the number of failed success criteria was small. Failed success criteria in Level AA include: SC 1.4.3 Contrast 
(Minimum), SC 1.4.4 Resize text and SC 2.4.6 Headings and Labels: Headings and labels describe topic or purpose. Again, in Level AAA conformance the State owned bank Web sites were the highest in failed success criteria. Also, the Web sites of the Foreign banks appeared to have the second highest failed success criteria. On the other hand, the Web sites of the Foreign banks having branches in Turkey have the least number of failed success criteria. Some of the failed success criteria include: SC 1.4.6 Contrast (Enhanced), the state-owned banks had the highest number of errors, whereas the foreign bank Web sites had the lowest. SC 2.4.9 Link Purpose (Link Only), and SC 2.4.10 Section Headings. Finally, Table 1 shows the number of accessibility errors of the homepage of the websites of the banking based on the level of conformance. From the results, it is clear that the homepages of the foreign banks was the highest in failing the three levels of conformance, which indicates the need for a quick remedy.

Concisely, all the thirty two websites of the four type of bankings require to present higher conformance levels to accessible web page design since they all violate most of the analyzed checkpoints. According to the results, the Foreign Banks Having Branches in Turkey have less accessibility errors compared to the other three banking types, whereas the Web sites of foreign banks had the highest number of errors. Banks with a higher accessibility error need to pay greater attention in providing services to vulnerable groups like persons with disabilities.

Table 1. Number of accessibility errors

\begin{tabular}{|l|l|l|l|l|}
\hline \multicolumn{1}{|c|}{ Checkpoints } & $\begin{array}{c}\text { State-owned } \\
\text { Banks }\end{array}$ & $\begin{array}{c}\text { Privately-owned } \\
\text { Banks }\end{array}$ & $\begin{array}{c}\text { Foreign } \\
\text { Banks }\end{array}$ & $\begin{array}{c}\text { Foreign Banks } \\
\text { Having Branches } \\
\text { in Turkey }\end{array}$ \\
\hline Conformance Level A & & & & \\
\hline 1.1 .1 & 78 & 876 & 1263 & 12 \\
\hline 1.3 .1 & 12 & 184 & 158 & 1 \\
\hline 2.1 .1 & 29 & 2 & & 26 \\
\hline 2.2 .1 & & & 1 & \\
\hline 2.2 .2 & & & & 1 \\
\hline 2.4 .2 & & & 2 & \\
\hline 2.4 .4 & 9 & 91 & 75 & 1 \\
\hline 3.1 .1 & 3 & 8 & 10 & 3 \\
\hline 3.2 .2 & & & 18 & \\
\hline 3.3 .2 & 7 & 59 & 52 & 1 \\
\hline 4.1 .1 & & 6 & 122 & \\
\hline 4.1 .2 & & & 42 & \\
\hline Conformance Level AA & & & & \\
\hline 1.4 .3 & 9 & 77 & 22 & 2 \\
\hline 1.4 .4 & 38 & 99 & 9 & 22 \\
\hline 2.4 .6 & & 1 & 1 & 3 \\
\hline Conformance Level AAA & & & & \\
\hline 1.4 .6 & 274 & 43 & 22 & 2 \\
\hline 2.1 .3 & & & 1 & \\
\hline 2.2 .4 & & & 4 & 195 \\
\hline 2.4 .9 & & & 5 & \\
\hline 2.4 .10 & & & 1 & \\
\hline 3.2 .5 & & & & \\
\hline
\end{tabular}




\subsection{Quality in Use Analysis}

The Response time of a website is a kind of indicator, which is usually tested by measuring, their throughput and load time. The First measurements were utilized on the download time, response time and mobile loading speed of banking websites using the websitepulse, Pingdom and PageSpeed Google tools for the quality and performance analysis. According to the results showed in Table 2, the best score was obtained from the websites Foreign Banks Having Branches in Turkey with the average load time being $4.31 \mathrm{~s}$, ranging from 1,06 to $10,96 \mathrm{~s}$. the best score was obtained from the websites of state owned banks with the average response time being $0.96 \mathrm{~s}$, ranging from 0,601 to $1,278 \mathrm{~s}$. The average load speed of the privately owned banking websites was higher at $10,57 \mathrm{~s}$; however, the maximum time $(34,41 \mathrm{~s})$ was lower than that of privately owned banking websites. The websites of state owned bankings had an average load time of $9.32 \mathrm{~s}$, with the minimum and maximum being 5.18 and $15.8 \mathrm{~s}$, respectively. The lowest speed among the tested websites belonged to the privately owned banking websites with an average load time of $10.57 \mathrm{~s}$ and a maximum of 34,41 min., the best score was obtained from the websites of privately owned banks with the average mobile loading speed time being $47.78 \mathrm{~s}$, ranging from 25 to $65 \mathrm{~s}$. (Table 2).

Following the download times, the total number of components in the design of websites was measured. These components, including images, style sheets and scripts, comprise large part of website traffic and can slow down the load time of websites by increasing the number of HTTP requests. The results presented in Table 2 shows that the average number of total HTTP requests in the websites of Foreign Banks Having Branches in Turkey was 44,6, with the minimum and maximum numbers being 21 and 95 , respectively. The number of requests in the privately owned bank websites was higher with an average of 115.78 requests, the minimum and maximum being 11 and 217 requests, respectively. The evaluation of state owned bank websites showed that the average number of HTTP requests was 87.67, ranging from 41-128. Similar results were obtained for the size of the websites: The lowest and highest average sizes were obtained from the Foreign Banks websites Having Branches in Turkey and privately owned banking websites at 1.05 and 2.47 megabytes, respectively. Detailed information regarding the number of components is given in Table 2 . Broken links were detected in $100 \%$ of the state owned banking websites, $75 \%$ of the privately owned banking websites, $95 \%$ of the foreign banking websites and $80 \%$ of the Foreign Banks websites Having Branches in Turkey. Moreover, the lowest numbers of broken links were observed in the websites of the Foreign Banks websites Having Branches in Turkey and foreign banks, with the maximum number being 6 . In contrast, the maximum numbers of broken links in the websites of foreign banks and provately owned banking websites were 117441 and 42955, respectively (Table 2).

According to the results obtained using the Pingdom tool, the overall average performance of the websites was as follows: The highest average score was obtained from the websites of the Foreign Banks Having Branches in Turkey that scored 76.20 out of 100 points, followed by the foreign banking websites ( 75 points).

For HTML and CSS validation results, only 2 web pages (4\%) have the zero html mark-up errors and 2 web pages (4\%) CSS validation errors (Table 2). ARIA, another standard of the $\mathrm{W} 3 \mathrm{C}$, asserts the lack of accessibility of many web pages. Regarding the 
use of ARIA, WAVE has been used to detect ARIA features in the analysed websites. Only 22 web sites (69\%) present some use of ARIA features.

The security vulnerabilities present in 32 selected website has been assessed by using SSLv3 POODLE vulnerability scanner tool and the result is, 16 out of $32(50 \%)$ assessed websites have one or more high-severity vulnerability. The SSL 3.0 vulnerability stems from the way blocks of data are encrypted under a specific type of encryption algorithm within the SSL protocol. The POODLE attack takes advantage of the protocol version negotiation feature built into SSL/TLS to force the use of SSL 3.0 and then leverages this new vulnerability to decrypt select content within the SSL session.

Table 2: Usability Traits $(\mathrm{N}=32)$

\begin{tabular}{|l|l|l|l|l|}
\hline & \multicolumn{1}{|c|}{$\begin{array}{c}\mathrm{SO} \\
(\mathrm{N}=3)\end{array}$} & \multicolumn{1}{|c|}{$\begin{array}{c}\mathrm{PO} \\
(\mathrm{N}=9)\end{array}$} & \multicolumn{1}{|c|}{$\begin{array}{c}\mathrm{NB} \\
(\mathrm{N}=15)\end{array}$} & $\begin{array}{c}\text { FBHBT } \\
(\mathrm{N}=5)\end{array}$ \\
\hline Total HTTP requests & & & & \\
\hline Average & 87,67 & 115,78 & 56,94 & 44,6 \\
\hline Min. & 41 & 11 & 12 & 21 \\
\hline Max. & 128 & 217 & 144 & 95 \\
\hline Total size (MB) & & & & \\
\hline Average & 2,17 & 2,47 & 1,63 & 1,05 \\
\hline Min. & 1,9 & 0,74 & 0,31 & 0,49 \\
\hline Max. & 2,6 & 4,88 & 4,78 & 1,88 \\
\hline Total images & & & & \\
\hline Average & 66,67 & 74,23 & 27,2 & 20,4 \\
\hline Min. & 28 & 6 & 7 & 5 \\
\hline Max. & 97 & 205 & 74 & 58 \\
\hline Total scripts & & & & \\
\hline Average & 12 & 19,45 & 14,54 & 9,6 \\
\hline Min. & 9 & 3 & 2 & 1 \\
\hline Max. & 16 & 50 & 41 & 23 \\
\hline Total CSS & & & & \\
\hline Average & 3,67 & 8,89 & 5,14 & 5,6 \\
\hline Min. & 1 & 1 & 1 & 3 \\
\hline Max. & 55 & 32 & 16 & 13 \\
\hline Total Objects & & & & \\
\hline Average & 87,67 & 115,78 & 56,94 & 44,6 \\
\hline Min. & 41 & 11 & 12 & 21 \\
\hline Max. & 128 & 217 & 144 & 95 \\
\hline IMAGES_SIZE & 1,59 & 1,48 & 1,02 & 0,39 \\
\hline Average & 1,38 & 0,37 & 0,09 & 0,001 \\
\hline Min. & 1,98 & 3,54 & 4,30 & 1,05 \\
\hline Max. & 0,35 & 0,49 & 0,49 & 0,18 \\
\hline SCRIPT_SIZE & & & & \\
\hline Average & & & & \\
\hline & & & & \\
\hline
\end{tabular}




\begin{tabular}{|l|l|l|l|l|}
\hline Min. & 0,19 & 0,13 & 0,05 & 0,02 \\
\hline Max. & 0,60 & 1,02 & 1,94 & 0,30 \\
\hline CSS_SIZE & & & & \\
\hline Average & 0,06 & 0,1 & 0,08 & 0,05 \\
\hline Min. & 0,02 & 0,005 & 0,005 & 0,01 \\
\hline Max. & 0,08 & 0,32 & 0,19 & 0,08 \\
\hline Load time & & & & \\
\hline Average & 9,32 & 10,57 & 7,59 & 4,31 \\
\hline Min. & 5,18 & 4 & 1,54 & 1,06 \\
\hline Max. & 15,8 & 34,41 & 26,36 & 10,96 \\
\hline Response Time & & & & \\
\hline Average & 0,96 & 3,99 & 3,14 & 3,11 \\
\hline Min. & 0,601 & 0,639 & 0,829 & 1,065 \\
\hline Max. & 1,278 & 17,683 & 7,931 & 8,968 \\
\hline Performance & & & & \\
\hline Average & 71 & 75 & 76,14 & 76,2 \\
\hline Min. & 64 & 62 & 65 & 56 \\
\hline Max. & 82 & 88 & 87 & 87 \\
\hline $\begin{array}{l}\text { Markup (HTML) Validation } \\
\text { (Number) (zero errors) }\end{array}$ & & & & \\
\hline Average & 68,67 & 86,67 & 11,69 & 33,60 \\
\hline Min. & 49 & 9 & 1 & 1 \\
\hline Max. & 80 & 167 & 54 & 143 \\
\hline $\begin{array}{l}\text { CSS Validation (Number) (zero } \\
\text { errors) }\end{array}$ & & & & \\
\hline Average & 108 & 232 & 91,46 & 95,80 \\
\hline Min. & 90 & 4 & 0 & 2 \\
\hline Max. & 125 & 996 & 555 & 288 \\
\hline Broken Link >=1 & & & & \\
\hline Average & 4719,33 & 5293,44 & 9068,47 & 3 \\
\hline Min. & 201 & 0 & 0 & 0 \\
\hline Max. & 9200 & 42955 & 117441 & 6 \\
\hline Mobile Loading Speed & & & & \\
\hline Average & 53,33 & 47,78 & 56,2 & 52,2 \\
\hline Min. & 32 & 25 & 12 & 39 \\
\hline Max. & 73 & 65 & 82 & 66 \\
\hline ARIA Usage & & & & \\
\hline Average & 156 & 31 & 56,29 & 15 \\
\hline Min. & 0 & 0 & 0 & 3 \\
\hline Max. & 385 & 41 & 84 & 33 \\
\hline Nes0-Se Ora & & & \\
\hline
\end{tabular}

Note: $\mathrm{SO}=$ State Owned; $\mathrm{PO}=$ Privately Owned; $\mathrm{FB}=$ Foreign Banks; FBHBT=Foreign Banks Having Branches in Turkey 


\section{Conclusion}

In this study, banking web sites have been carried out with dimensions such as accessibility, quality and vulnerability are among the most critical and crucial quality criteria for banking websites to provide better services and to disseminate information and services across all their customers including the disabled and elderly individuals. Each dimension was measured by a series of specific tools. The analysis of the given websites have been utilised based on seventeen quality dimensions (for instance; response time, page size and broken links etc.). Overall, it can be said that web developers responsible for banking websites should follow and encourage the use of recognised guidelines when designing website. It is clear in this study that more effort is required to meet these criteria in the context of website design to make banking websites to be more effective, highly user-centric and easy accessible for the customers. The result of this study confirmed that the website presence of banking website is neglecting accessibility, usability, performance, vulnerability and quality criteria.

In the accessibility assessment, the findings indicated that the majority of banking websites in Turkey still have a lot to do to become accessible websites based on the WCAG 2.0 standards. Websites $56 \%$ of banking web sites have Level AA, and ninety eight Level A. However, about $98 \%$ of banking web sites in the Turkish Republic fail to pass Level A checkpoints for accessibility errors. These results suggest that guidelines such as WCAG 2.0 should be exploited. As internet banking continues to attain acceleration as a key means of dissemination of financial information and services to customers, there is an ever increasing need to ensure the accessibility of banking websites so that all customers can experience the benefits of internet banking. In the current study, the accessibility of deposit bank websites in Turkey was assessed based on WCAG 2.0 standards. The key aim is to determine conformance levels with WCAG 2.0 and also examine which macro factors were associated with banking websites' accessibility in Turkey. The results of analysis pointed out that the majority of banking websites in Turkey still have errors to become accessible websites based on the WCAG 2.0 standards. This signifies the need for banks in Turkey to adopt appropriate strategies for advancing the accessibility of their bank websites. With this paper, researcher accomplished to achieve researcher's major aim which is, delivering indicators on the actual accessibility levels presented by the banks with activities in Turkey. As the presented results revealed, a substantial amount of accessibility errors were identified on all the websites belonging to the analysed sample. Indeed, the findings indicated that the majority of banking websites in Turkey still had a long way to go to become accessible based on the WCAG 2.0 standards. The accessibility levels presented by the websites of the target group remains poor.

The main vulnerability concern about banking web sites is that $50 \%$ have one or more high-severity vulnerability (Poodle attack). Some sites appeared to have both high-severity and medium-severity vulnerabilities and have passwords transmitted over HTTP. Banking websites are often the target for hackers, therefore these vulnerabilities are real threats to the security and privacy of financial and personal information shared by users and the banks.

In the future research studies, the data can be collected from the objective and subjective views of the bank websites from the user's perspective. Furthermore, different variables related with these sites can be added such as availability, security and culture. To develop a usable, accessible and secure e-banking infrastructure, the 
findings from this paper suggest, guidelines and experience of the best internet banking practices should be studied and updated the current websites in accordance with WCAG 2.0 guidelines. Great effort is needed for bank web sites in the Turkey to improve accessibility, usability and security.

\section{REFERENCES}

Achour, H., Bensedrine, N. (2005). An evaluation of internet banking and online brokerage in Tunisia. In: Proceedings of the First International Conference on EBusiness and E-learning (EBEL) (pp.147-158). Amman, Jordan.

Akgül, Y. and Vatansever, K. (2016a). Web accessibility evaluation of government websites for people with disabilities in Turkey. J. Adv. Manag. Sci., 4 (3), 201210.

Akgül, Y. and Vatansever, K. (2016b). Web Content Accessibility of Municipal Web Sites in Turkey. J. Adv. Manag. Sci., Vol. 7 No. 1, 43-48.

Akgül, Y. (2016a). Quality Evaluation of E-Government Websites of Turkey", 11th Iberian Conference on Information Systems and Technologies, 15th and 18th of June 2016, at Gran Canaria, Canary Islands, Spain.

Akgül, Y. (2016b). Analysis on Design Issues of E-Government Websites of Turkey. IX. European Conference on Social and Behavioral Sciences - February 3-6, 2016, Paris, France.

Ali, L., Jahankhani, H. \& Jahankhani, H. (2007). eAccessibility of Online Banking Services. In C. Montgomerie \& J. Seale (Eds.), (pp. 4054-4060) Proceedings of EdMedia: World Conference on Educational Media and Technology 2007.

ATRC at the University of Toronto, Date of Access: 07.12.2017, Retrieved from: atutor.ca/achecker.

Awamleh, R., Fernandes, C. (2005). Internet banking: an empirical investigation into the extent of adoption by banks and the determinants of customer satisfaction in the United Arab Emirates. Journal of Internet Banking and Commerce, 10 (1), 110 .

Banks Association of Turkey (BAT) (2017). Date of Access: 07.12.2017, Retrieved from: https://www.tbb.org.tr/Content/Upload/istatistikiraporlar/ekler/862/DijitalInternet-Mobil_Bankacilik_Istatistikleri-Eylul_2017.pdf

Banks Association of Turkey (BAT) (2017) Date of Access: 07.12.2017, Retrieved from:

https://www.tbb.org.tr/modules/banka-bilgileri/banka_Listesi.asp?tarih=9/9/2016

Bonsón-Ponte E, Escobar-Rodri'guez T, Flores-Muñoz F. (2008). Navigation quality as a key value for the webpage of a financial entity. Online Inf Rev., 32 (5), 623634.

Celic, S., Faulkner, S., and Arch, A. (2004). A Look at Internet Banking Accessibility in Australia," in AusWeb04. The Tenth Australian World Wide Web Conference, Seaworld Nara Resort, Gold Coast, 3-7 July 2004. 
Chin-Shan W, Cheng F, Lin H. (2004). Web site usability evaluation of internet banking in Taiwan. J Internet Bank Commer, 9 (1)

CSS Validator, (1994-2009), CSS Validation Service, Date of Access: 07.12.2017, Retrieved from: http://jigsaw.w3.org/css-validator.

Diniz, E., Porto, M.R., Adachi, T., 2005. Internet banking in Brazil: evaluation of functionality, reliability, and usability. The Electronic Journal of Information Systems Evaluation, 8 (1), 41-50.

Eduardo D, Morena PR, Tomi A (2005) Internet banking in Brazil: evaluation of functionality, reliability and usability. Electron J Inf Sys Eval., 8 (1), 41-50.

Fast Link Checker 1.6.0.0587, (2005-2009), Web Tweak Tools.Net, Date of Access: 07.12.2017, Retrieved from: http://www.fastlinkchecker.com/

Firat, S. (2010). People with disabilities in Turkey: An overview. Information Technologies, Management and Society, 3 (2), 51-54.

Frankelius, P. (2009). Questioning two myths in innovation literature. J High Technol Manag Res., 20 (1), 40-51.

Guru, K.B., Shanmugam, B., Alam, N., Perera, J.C. (2003). An evaluation of internet banking sites in Islamic countries. Journal of Internet Banking and Commerce, 6 (1), 1-10.

HTML Validator, (1994-2009), Markup Validation Service, Date of Access: 07.12.2017, Retrieved from: http://validator.w3.org

Internetlivestats (2017) Date of Access: 07.12.2017, Retrieved from: http://www.internetlivestats.com/internet-users-by-country

Ismailova, R. 2015. Web site accessibility, usability and security: a survey of government web sites in Kyrgyz Republic. Universal Access in the Information Society, DOI 10.1007/s10209-015-0446-8 pp.43-48.

Jati, H., Dominic, D.D. 2009. Quality evaluation of e-government website using web diagnostic tools: Asian case. In Information Management and Engineering, 2009. ICIME'09. International Conference on, pp.85-89.

Kaur, A., Dani, D., 2014. Banking websites in india: an accessibility evaluation. CSI Trans. ICT, 2, 23-34.

Kaur, Arvinder and Dani, Diksha. (2013). The Web Navigability Structure of EBanking in India. I.J. Information Technology and Computer Science, 05, 29-37.

La Porte, M.T., Demchak, C. C. and Friis, C. (2001). Webbing Governance: Global Trends across National Level Public Agencies. Communications of the ACM, vol. 44, no. 1, 63-67. 
Lichtenstein, S., and Williamson, K. (2006). Understanding Consumer Adoption of Internet Banking: An Interpretive Study in the Australian Banking Context. Journal of Electronic Commerce Research, (7:2), 50-66.

Lorca, Pedro, Javier de Andrés, and Ana Belén Martínez. (2015). Does Web accessibility differ among banks?. World Wide Web, 1-23.

Manhas, J. 2014. Analysis on Design Issues of E-Government Websites of India. International Journal of Advanced Research in Computer Science and Software Engineering, Volume 4, Issue 2, 646-650.

Martins, J., Gonçalves, R., Mamede, H., Pereira, J., Martins, M. (2010). Web Accessibility 2.0 - Web accessibility status of the Banks with activities in Portugal. In DSAI 2010, Oxford, Reino Unido.

Martínez, Ana B. Javier De Andrés, Julita García. (2014). Determinants of the Web accessibility of European banks. Information Processing \& Management, Volume 50, Issue 1, 69-86,

Nouman, N. (2012). Website Content Accessibility of Banks Websites in Pakistan Using WCAG 2.0. ARPN Journal of Systems and Software, VOL. 2, NO. 1, 2326.

Orji, R. O. (2010). Analysis of Usability and Accessibility Problems of Financial Sectors' Website using Visitor-based Evaluation Technique, 2nd International Conference on Information and Multimedia Technology (ICIMT 2010), pp. V1252-V1-257.

Pagespeed (2017) https://developers.google.com/speed/pagespeed visited on 10/12/2017

Paynter, J., Chung, W. (2002). An evaluation of internet banking in New Zealand. In: Proceedings of the 35th Hawaii International Conference on System Sciences, USA.

Pingdom (2017) Tools.pingdom.com visited on 10/12/2017

Quinn, G. (2009). The United Nations Convention on the Right of Persons with Disabilities: Toward a New International Politicsof Disability. Texas Journal on Civil Liberties and Civil Rights, 15(1), 33-52.

Statista, (2017). Date of Access: 07.12.2017, Retrieved from: https://www.statista.com/statistics/273018/number-of-internet-users-worldwide/

Thechnosite group (2004). Accessibility of Bank websites in Spain, Date of Access: 07.12.2017, Retrieved from: http:// www.discapnet.es/discapnet/castellano

Thorp, J., \& Henry, S. L..(2008). Introduction to Web Accessibility. W3C (MIT, ERCIM, Keio). Date of Access: 07.12.2017, Retrieved from: http://www.w3.org/WAI/intro/accessibility.php.

Turkish Statistical Institute (TSI). (2002). Turkey Disability Survey. Publication Number 291. Ankara: TSI. Turkish Statistical Institute (TSI). (2017). Date of Access: 07.12.2017, Retrieved from: http://www.tuik.gov.tr/PreTablo.do?alt_id=1028 
Turkish Statistical Institute (TSI). (2017). Date of Access: 07.12.2017, Retrieved from: http://www.tuik.gov.tr/PreHaberBultenleri.do?id=18660

United Nations Enable (UNE). (2013). Some Facts about Persons with Disabilities. $\begin{array}{lll}\text { Retrieved on } 12 \text {, } & \text { March }\end{array}$ 2013fromhttp://www.un.org/disabilities/convention/facts.shtml

United Nations, (2017) Date of Access: 07.12.2017, Retrieved from: http://www.un.org/disabilities/documents/maps/enablemap.jpg Accessed: 20.12.2017

Vijayan, P., Shanmugam, B. (2003). Service quality evaluation of internet banking in Malaysia. Journal of Internet Banking and Commerce, 8 (1), 1-10.

WebAIM, “WAVE". Date of Access: 07.12.2017, Retrieved from: http://wave.webaim.org/

Web Content Accessibility Guidelines 1.0. Date of Access: 07.12.2017, Retrieved from: http://www.w3.org/TR/WCAG10/

Websiteoptimization (2017) Date of Access: 07.12.2017, Retrieved from: http://www.websiteoptimization.com visited on 10/12/2017

Websitepulse (2017) Date of Access: 07.12.2017, Retrieved from: http://www.websitepulse.com/ visited on 10/12/2017

Wenham, D., Zaphiris, P. (2003). User interface evaluation methods for internet banking web sites: a review, evaluation, and case study. In: Jacko, Stephanidis, J.C. (Eds.), Human-Computer Interaction, Theory and Practice. Lawrence Erlbaum, Mehwah, USA, pp. 721-725.

World Health Organization (WHO). (2011). World Report on Disability. Date of Access: 07.12.2017, Retrieved from: http://www.who.int/about/licensing/copyright form/en/index.html

World Wide Web Consortium (W3C). Web accessibility evaluation tools list. Date of Access: 07.12.2017, Retrieved from: http://www.w3.org/WAI/ER/tools/

World Wide Web Consortium (W3C). Web content accessibility guidelines (WCAG) overview. Date of Access: 07.12.2017, Retrieved from: http://www.w3.org/WAI/intro/wcag.php

World Wide Web Consortium (W3C). Web content accessibility guidelines (WCAG) overview. Date of Access: 07.12.2017, Retrieved from: http://www.w3.org/TR/WCAG10

Zhang, P., Dran, G. (2001). Expectations and ranking of website quality features: results of two studies on user perceptions. In: Proceedings of the 34th Hawaii International Conference on System Sciences. 